\title{
RECONFIGURAÇÃO DO ENSINO SUPERIOR EM TEMPOS DE GLOBALIZAÇÃO
}

\author{
Carlos Benedito Martins ${ }^{1}$
}

\begin{abstract}
RESUMO: O artigo aborda transformações no Ensino Superior contemporâneo em escala internacional, impulsionadas pela globalização. Apoia-se em uma revisão recente da literatura pertinente ao tema abordado. Enfoca um conjunto de ideias recentes, que procura estreitar os vínculos das universidades com as demandas do campo econômico, o qual tende a comprometer sua autonomia diante de forças externas, cujo princípio marcou a trajetória histórica das universidades. Em sua conclusão, o artigo salienta que, apesar de ser pressionada pelo processo de globalização para responder de forma utilitária às demandas do campo econômico, em função do incremento de fluxos de conhecimentos que ocorre no plano mundial, as universidades comportam a possibilidade de produzir um conhecimento crítico com relação à própria dinâmica da globalização.
\end{abstract}

Palavras-chave: Globalização. Espaço transnacional do Ensino Superior. Knowledge society. New public management. Empreendedorismo.

\section{RECONFIGURATION OF THE HIGHER EDUCATION IN GLOBALIZATION TIMES}

\begin{abstract}
The article addresses the transformations in contemporary Higher Education on an international scale, driven by globalization. The paper is based on a recent review of the literature relevant to the topic addressed. This text focuses on a set of recent ideas that seek to strengthen the links between universities and the demands of the economic field, which tends to compromise their autonomy in the face of external forces, whose principle has marked the history of universities.In its conclusion, the article stresses that, despite being pressured by the globalization process to respond in a utilitarian way to the demands of the economic field, due to the increase in knowledge flows, that occurs at the global level, universities have the possibility of producing critical knowledge regarding the dynamics of globalization process itself.
\end{abstract}

Keywords: Globalization. Transnational space of Higher Education. Knowledge society. New public management. Entrepreneurship.

\footnotetext{
Este texto insere-se na pesquisa Construção Social de um Novo Modelo de Ensino Superior em Tempos de Globalização, que vem sendo realizada pelo autor, com apoio de Bolsa de Produtividade CNPq.

1.Departamento de Sociologia - Universidade de Brasília - Brasília (DF), Brasil. E-mail: carlosb@unb.br

Editor de Seção: Antonio Alvaro Soares Zuin
} 


\title{
RECONFIGURACIÓN DE LA EDUCACIÓN SUPERIOR EN TEMPOS DE GLOBALIZACIÓN
}

\begin{abstract}
RESUMEN: El artículo aborda las transformaciones en la educación superior contemporánea a escala internacional, impulsadas por la globalización. El artículo se basa en una revisión reciente de la literatura relevante al tema abordado. El texto enfoca un conjunto de ideas recientes, que busca fortalecer los vínculos de las universidades con las demandas del campo económico, que tiende a comprometer su autonomía frente a fuerzas externas, cuyo principio marcó la trayectoria histórica de las universidades. Para concluir, el artículo destaca que, a pesar de estar presionados por el proceso de globalización para responder de manera utilitaria a las demandas del campo económico, debido al aumento de los flujos de conocimiento que se da a nivel global, las universidades apoyan la posibilidad de producir un conocimiento crítico sobre la dinámica misma de la globalización.
\end{abstract}

Palabras-clave: Globalización. Espacio transnacional de educación superior. Sociedad del conocimiento. Nueva administración pública. Emprendimiento.

\section{Introdução}

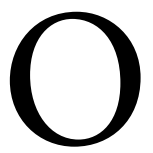

Ensino Superior contemporâneo, em nível internacional, encontra-se imerso num turbilhão de profundas transformações sociais, políticas, econômicas e culturais que perpassam as sociedades contemporâneas em ritmos e formatos diversos. Essas transformações-têm sido impulsionadas pelo processo de globalização, cuja manifestação tornou-se mais visível, socialmente, nas últimas décadas do século passado.

A partir dos anos 1980, o processo de globalização passou a ocupar um espaço na agenda da sociologia por meio dos trabalhos pioneiros de Immanuel Wallerstein, Bryan Turner, Roland Robertson, Anthony Giddens, Ulrich Beck, Randall Collins, Martin Albrow, Stuart Hall, Margaret Archer, Manuel Castells, entre outros. A partir de diferentes perspectivas teóricas, esses autores voltaram suas atenções para a emergência de processos e estruturas que ocorriam além das fronteiras nacionais, entre os quais: o surgimento de uma economia global que incorporava desigualmente nações no contexto de uma nova divisão internacional do trabalho; a desregulamentação do comércio mundial; a ascensão de um capitalismo financeiro; novas tecnologias de comunicação, que passaram a interligar indivíduos em diferentes pontos no planeta; a formação de blocos geopolíticos supranacionais; a proliferação de agências multilaterais; a aceleração nas pesquisas científicas e tecnológicas; a manifestação de riscos ambientais globais; a eclosão de movimentos sociais voltados para a defesa de direitos humanos em esfera planetária; etc. ${ }^{1}$

Ao analisar o fenômeno da globalização, Turner e Khondker destacam que qualquer investigação sociológica que pretenda abordar uma nação, uma região, uma cidade, pequena ou remota, e/ou um fenômeno específico, como o Ensino Superior, corre o risco de se tornar incompleta, caso não contemple a presença de fenômenos que se manifestem além das fronteiras nacionais (TURNER; KHONDKER, 2010; TURNER; ELLIOT, 2012; SASSEN, 2007, 2014; BECK, 2006, 2016; ELLIOT, 2013).

O presente artigo tem o objetivo de abordar determinadas tendências de transformações no Ensino Superior contemporâneo, em escala internacional, no contexto da globalização, assinalando as relações recíprocas entre esses dois fenômenos. Para tanto, parte-se do pressuposto de que, por um lado, a dinâmica 
do processo de globalização tem impactado o modus operandi do Ensino Superior, tanto na sua configuração espacial quanto na cultura acadêmica no interior das universidades; e, por outro, o Ensino Superior e as instituições que o integram tenham se tornado atores relevantes na dinâmica do processo de globalização, ao constituírem um dos loci centrais de informações em larga escala e formação de quadros profissionais.

Num primeiro momento, o artigo destaca que, com a globalização, ocorreu uma mudança na estruturação espacial do Ensino Superior, uma vez que esse não se confina mais somente nos territórios nacionais. Assinala-se que, ao lado da presença de sistemas nacionais de Ensino Superior, que se desenvolveram no decurso de seus respectivos contextos históricos, formou-se, gradativamente, nas últimas décadas, um novo locus de sua atuação; ou seja, um espaço transnacional de Ensino Superior. Num segundo momento, o artigo aborda mudanças na cultura acadêmica da universidade, na medida em que uma série de ideias tem procurado vincular essa instituição ao processo de produtividade econômica, ressaltando a constiuição dos conceitos de knowledge society e new public management (NPM).

Ambos os conceitos têm sido utilizados em documentos de organismos internacionais e políticas nacionais de educação, bem como em trabalhos acadêmicos, de forma acrítica, como se fossem categorias naturais do pensamento, descuidando-se de avaliar as dimensões ideológica, instrumental e normativa que os conceitos comportam. ${ }^{2}$ Ao realizar brevemente a constituição dessas duas noções, o artigo assume o pressuposto de que o trabalho reflexivo nas ciências sociais implica a necessidade de historicizar, de forma recorrente, a gênese social das categorias de pensamento e dos conceitos existentes num dado momento. Na ausência dessa historicização, corre-se o risco de se ser manipulado da forma mais insidiosa pela interiorização inconsciente de determinadas categorias de pensamento, utilizadas automática, recorrente e dominantemente nessas disciplinas. ${ }^{3}$

Como ocorre com vários temas na sociologia, não existe consenso conceitual a respeito do processo de globalização. Há diferentes visões, compreensões e, também, discordâncias sobre sua cronologia e seu impacto nas sociedades contemporâneas. ${ }^{4}$ No entanto, a conceituação formulada por Turner e Khondker orienta o presente artigo. Segundo eles, "globalização é um processo multidimensional que abarca as dimensões econômica, sociopolítica e cultural. Trata-se de um processo histórico que possui uma dimensão macro e também um nível micro, uma vez que afeta a consciência e a vida cotidiana dos indivíduos" (TURNER; KHONDKER, 2010). As mudanças provocadas pela globalização não deixam de ter um significativo impacto no Ensino Superior internacional contemporâneo, na medida em que estão ocorrendo aceleradas mutações tecnológicas, que pressionam as universidades para produzir um conhecimento que mantenha uma interface com esses avanços e com o cenário de competitividade entre os países. Este trabalho tem uma proximidade com o conceito de tipo ideal concebido por Max Weber, na medida em que procura formar um quadro de pensamento a respeito do Ensino Superior contemporâneo em escala internacional, partindo de determinadas relações e acontecimentos que ocorrem no seu interior, mediante a acentuação mental de determinados traços do seu funcionamento, como um meio de conhecimento de seu modus operandi, cujas manifestações empíricas podem assumir formas extremamente variáveis, dependendo de cada contexto histórico (WEBER, 1949).

\section{Local, Nacional e Global no Ensino Superior}

O processo de globalização tem apresentado novos desafios teóricos e metodológicos para as ciências sociais, que, por um longo período, concentraram suas análises nas sociedades nacionais. O ponto focal das investigações centradas nas sociedades nacionais tem procurado compreender o interior de cada uma, visando captar sua estrutura social, a articulação de suas instituições, seus padrões de desigualdades, 
modos de conflitos e processos de mudanças sociais. Nessa ótica, os sistemas educacionais têm sido enfocados basicamente a partir de sua vinculação com a especificidade histórica de cada sociedade nacional, de tal maneira que o Évolution Pédagogique en France, trabalho pioneiro de Durkheim, e, posteriormente, o American University, de Talcott Parsons e George Platt, constituem casos exemplares dessa orientação. $\mathrm{O}$ processo de globalização colocou em evidência a presença de estruturas econômicas, políticas, culturais, sociais e acadêmicas que se desenvolvem em escala mundial, dando origem a uma realidade original que impele à necessidade de adotar uma nova atitude teórica nas ciências sociais.

Diante dessa situação, vários autores têm criticado o recorrente comportamento teórico e metodológico de concentrar a análise dos diversos fenômenos sociais circunscrevendo-os tão-somente aos limites das sociedades nacionais, denominando essa postura nacionalismo metodológico ${ }^{4} \mathrm{Na}$ visão de Ulrich Beck, um dos expoentes que têm criticado o nacionalismo metodológico, a complexidade da condição humana não consegue ser compreendida levando-se em consideração apenas o nível nacional ou local. Ela exige articulações com o nível global. Para ele, a globalização não é não linear e pode assumir diferentes configurações. O global e o local não existem como polaridades econômica, política e cultural, mas princípios combinados e implicados mutuamente nas mais diferentes esferas da vida social do Estado-Nação. Em sua visão, a imbricação do nacional e do global situa a globalização no interior das sociedades nacionais. A esse fenômeno, esse autor dá o nome "cosmopolização", pois tende a transformar a consciência, as identidades e os valores nas condutas cotidianas dos indivíduos de maneira significativa nos espaços nacionais (BECK, 2006, 2016; CHERNILO, 2011, 2018; LEMERT, 2015).

Vários autores salientam que, apesar do processo de globalização, permanece nas análises sobre Ensino Superior a propensão a abordá-lo como fenômeno tipicamente endógeno, sem levar em consideração processos sociais que ocorrem além das fronteiras nacionais e mantêm interações recíprocas com os respectivos sistemas nacionais de ensino de terceiro grau (SHAHJAHAN; 2012; DALE; ROBERTSON, 2009; CANTWELL; MALDONADO-MALDONADO, 2009). Distanciando-se da postura do nacionalismo metodológico, este trabalho salienta que, no contexto da globalização, os níveis local, nacional e global mantêm relações de reciprocidade. ${ }^{5}$

Por um longo período, o Ensino Superior estruturou-se no interior das fronteiras das sociedades nacionais por meio de universidades, de tal forma que as duas designações - universidade e Ensino Superior foram apreendidas como termos equivalentes. A partir do final do século XIX, em várias partes do mundo, as universidades passaram a ter sua organização influenciada pelo modelo concebido, em 1810, por Humboldt, por ocasião da criação da Universidade de Berlim, que integrou as atividades de ensino e pesquisa e procurou mantê-la numa posição de relativa autonomia diante das demandas econômicas e políticas. Nessa concepção, permaneceu um contrato implícito entre universidade e sociedade. Em função do valor das atividades de produção de conhecimento, as demandas instrumentais da sociedade seriam atendidas de forma indireta, preservando-se a autonomia institucional da universidade. ${ }^{6} \mathrm{Na}$ esteira da expansão das universidades em vários países, formaram-se diversos sistemas nacionais de Ensino Superior, que assumiram características acadêmicas específicas, em função dos contextos social, político e cultural de suas respectivas sociedades. Inicialmente voltadas a uma clientela restrita, dotada de capital econômico e/ou cultural, as universidades passaram, pouco a pouco, a incorporar, em escala mundial, grupos sociais até então às suas margens. A partir da década de 1960, o Ensino Superior começou a dar sinais mais nítidos de transformações em sua morfologia em termos de aumento de instituições e número de matrículas, iniciando um processo de ampliação que se acelerou em escala mundial nas décadas seguintes (CHARLES; VERGER, 2012).

Paralelamente à expansão das universidades, ocorreu um processo de diversificação institucional; ou seja, o surgimento de estabelecimentos não universitários, como community colleges, nos Estados Unidos, 
Fachhochschule, na Alemanha, institut universitaires de recherche, na França e polytechnics, na Inglaterra, institutos de formação técnica etc. Nesse contexto, ocorreu a formação de sistemas nacionais de Ensino Superior hierarquizados em termos de prestígio acadêmico e social. Passaram a coexistir universidades de pesquisa e estabelecimentos voltados basicamente a atividades de ensino e formação de profissionais (PALFREYMAN; TAPPER, 2009).

A expansão e a diversificação institucionais, que levaram à criação de milhares de instituições, com milhões de estudantes nos cinco continentes, propiciaram uma condição favorável para o surgimento do espaço transnacional do Ensino Superior, que vem adquirindo maior visibilidade no processo de globalização. Tal espaço constituiu o resultado da prática social de uma pluralidade de atores institucionais e individuais, como governos nacionais e organizações supranacionais (p. ex., Organização para a Cooperação e Desenvolvimento Econômico; Banco Mundial; Unesco; Organização Mundial do Comércio etc.), cujas agendas de trabalho tendem a repercutir direta e/ou indiretamente nos sistemas nacionais de Ensino Superior. Neste espaço, ocorre também a ação de dirigentes de universidades nacionais, que procuram posicionar suas instituições nos rankings globais e atrair-estudantes estrangeiros para suas instituições, além da atuação de policy makers, que participam nas burocracias de seus países e, simultaneamente, mantêm interações com as agendas dos organismos supranacionais voltados para a educação.

Na medida em que o Ensino Superior não se confina mais nos limites dos territórios nacionais, torna-se oportuno destacar brevemente o surgimento de três fenômenos que contribuíram para a formação do espaço transnacional do Ensino Superior: 1) processo de desterritorialização do Ensino Superior; 2) incremento da mobilidade internacional dos estudantes; e 3) surgimento dos rankings globais, que serão abordados brevemente a seguir.

O deslocamento de universidades e/ou corporações educacionais que passam a atuar em outros países tem impulsionado o fenômeno da desterritorialização do Ensino Superior. Trata-se de um acontecimento relativamente recente, pois, até os anos 1980, eram poucas as universidades que ofereciam programas de ensino além de suas fronteiras nacionais. No entanto, a partir dos anos 1990, iniciou-se um claro deslocamento de instituições de Ensino Superior em escala continental, liderado por países como Estados Unidos, Inglaterra e Austrália. Esse movimento passou a ser denominado cross borderless education. (CUNNINGHAN et al., 2000).

O Acordo Geral sobre Comércio de Serviços (GATS; do inglês, General Agreement on Trade in Services), que entrou em funcionamento em janeiro de 1995, impulsionou o processo de desterritorialização do Ensino Superior, uma vez que possuía o objetivo de promover o livre comércio de serviços, removendo eventuais barreiras legais. A educação constitui um dos doze serviços cobertos pelo GATS. Portanto, o deslocamento de instituições e corporações educacionais para atuar em vários países encontra-se amparado nesse tratado (KING, 2004; KNIGHT, 2008, 2003). A partir de 2000, ocorreu uma expansão no processo de criação de novos campi, especialmente no Oriente Médio e no Sudeste Asiático, de tal forma que, em 2017, existiam 263 branch campi (GARRET, 2017; WILDAVSKY, 2010). Com a desterritorialização do Ensino Superior, ocorreu a constituição de grupos educacionais a partir de uma lógica empresarial. A criação da U21 Global é um caso exemplar nesse processo. Criada em 1997, em Melbourne, na Austrália, inicialmente por meio do consórcio de onze universidades estrangeiras, a U21 Global comporta, atualmente, 27 instituições, situadas em dezoito países, que oferecem cursos on-line nas áreas de administração de negócios e mídia social, com o objetivo de formar quadros profissionais para atuar na economia global. A U21 Global é integrada por universidades de prestígio acadêmico, como University of Birmingham, University of Edinburgh, University of Glasgow, University College Dublin, University of Hong Kong, National University of Singapore, Shanghai Jiao Tong University, University of Connecticut, University of California, Davis, University of Zurich etc. (KOSMUTZKY; PUTTY, 2016; BJARNASON, 2004). 
Embora a mobilidade acadêmica internacional possua uma longa tradição na história do Ensino Superior, o volume do deslocamento internacional dos estudantes nas últimas décadas difere em termos de grau e natureza. Nos primeiros anos da década de 1970, 500 mil estudantes tinham deixado seus países em busca da formação acadêmica em universidades estrangeiras. A partir dos 1990, houve uma rápida expansão dessa circulação e dados recentes apontam a existência de mais de 5 milhões de estudantes internacionais (IIE..., 2018). A intensidade desse novo fenômeno insere-se no processo de uma acirrada competição entre países e universidades para o recrutamento de estudantes considerados talentosos que, após receber a titulação acadêmica, possam eventualmente ser integrados em nichos de mercados de trabalho que exijam alta qualificação profissional. Por outro lado, ao mesmo tempo que vários países estão diminuindo o volume de subsídios públicos para o Ensino Superior, a atual mobilidade, em larga medida, tem sido pautada pela lógica de busca de ganhos econômicos. Tanto é assim que se verifica um aumento no valor de taxas escolares para estudantes estrangeiros em várias universidades (COLLINI, 2012, 2018).

Os dados mostram que a maior incidência de absorção de estudantes internacionais ocorre em países como Estados Unidos (24\%), Reino Unido (11\%), China (10\%), Austrália (7\%), Canadá (7\%), França (7\%), Rússia (6\%) e Alemanha (6\%). Todos os demais países somam 23\%. Não deixa de ser significativo que quase metade desses estudantes esteja concentrada em países com posições destacadas nos rankings globais e que usam o inglês como idioma. Os dados indicam que a concorrência por recrutamento de estudantes internacionais tende a se tornar mais intensa em curto e longo prazos. O governo do Canadá planeja recrutar 450 mil estudantes até 2022 (IIE..., 2018).

A iniciativa de classificar o desempenho e o prestígio acadêmico de instituições de Ensino Superior não constitui um fato recente. Durante longo tempo, essa atividade concentrou seu foco fundamentalmente nos sistemas nacionais de Ensino Superior. A partir do início do ano 2000, ocorreu a emergência de vários rankings globais de classificação de instituições superior dessa modalidade de ensino. De certa forma, isso expressa uma metáfora do processo de globalização do Ensino Superior, pois possui conexões com um conjunto de mudanças em curso, tais como expansão e diversificação, hierarquização dos sistemas nacionais de Ensino Superior e surgimento de um novo ethos acadêmico, o qual privilegia a competição por prestígio entre universidades e países etc. Na medida em que o Ensino Superior vem se tornando ator cada vez mais estratégico na produção de novos conhecimentos e um componente relevante no processo de competitividade econômica na globalização, seu desempenho também passa a ser comparado em escala internacional (MARGINSON, 2014, 2011; RAUHVARGERS, 2013; HAZELKORN, 2011, 2014).

Um dos primeiros rankings globais foi o Academic Ranking of World Universities (ARWU), editado em 2003 pelo Instituto de Ensino Superior da Shanghai Jiao Tong University. Posteriormente, surgiu mais de uma dezena de rankings globais, constituindo, de certa forma, um campo especializado em classificar internacionalmente as instituições de Ensino Superior (LUKE, 2011). Parte expressiva da bibliografia sobre os rankings globais oscila entre uma perspectiva analítica e uma postura valorativa, sugerindo estratégias para as universidades conquistarem posições de destaque. Afastando-se dessa postura normativa, o que se deseja salientar é a centralidade que esses rankings globais adquiriram no espaço transnacional de Ensino Superior e o seu impacto na orientação de um conjunto de atores. Nessa direção, tendem a guiar a conduta de governos para impulsionar suas universidades no plano internacional e influenciam reitores, que procuram criar estratégias para tornar suas instituições competitivas internacionalmente. Também impactam a prática acadêmica dos docentes - que desfrutam de posição de destaque no espaço transnacional de Ensino Superior, ou desejam alcançá-la -, pressionando-os a publicar em periódicos internacionais. Ao ser internalizada, consciente e/ou inconscientemente, por esses atores, a cultura dos rankings globais converteu-se não apenas num poderoso instrumento que pauta suas ações, mas também num instrumento de constante vigilância 
institucional. Tudo com objetivo de ocupar posições de destaque nos rankings globais (SAUDER; ESPELAND, 2009). Por outro lado, esses rankings apontam a existência de relações de poder e dominação acadêmica no espaço transnacional do Ensino Superior, na medida em que atestam a presença de uma estrutura desigual entre as universidades de diferentes países. De forma reiterada, as vinte primeiras colocações desses rankings têm sido ocupadas por universidades norte-americanas, seguidas de algumas inglesas e uma ou outra europeia; ou seja, por instituições que possuem elevados recursos humanos e materiais. Essas instituições de elite geralmente situam-se em cidades globais e/ou em suas adjacências, abrigam as principais editoras universitárias e as revistas de maior reputação científica. Tais circunstâncias concorrem favoravelmente para a dominação simbólica do conhecimento produzido e divulgado nessas e em outras universidades destacadas nos rankings globais (KENNEDY, 2015). A divulgação dos resultados dos rankings globais desperta a atenção de governos nacionais e dirigentes de universidades pelas atividades de ensino, pesquisa, recrutamento de docentes e estudantes, infraestrutura e modos de gestão adotados nas instituições de prestígio, a fim de reproduzir esses padrões acadêmicos. ${ }^{7}$

\section{Mudanças na Produção Acadêmica da Universidade}

Ao longo do tempo, formou-se uma linhagem de pensamento que buscou enfatizar a autonomia da universidade diante das demandas religiosas, políticas e econômicas, o que se prolonga desde as Conferências do Cardeal Newman, em 1852, transformadas na publicação The Idea of University, a qual teve continuidade com as reflexões de Humboldt, Karl Jaspers, Habermas, Stephen Ball, Stefan Collini entre outros. Apesar de eventuais diferenças de posicionamento de integrantes dessa vertente, os autores consideram universidade um espaço intelectual no qual professores e estudantes compartilham o ideal de produzir o conhecimento como finalidade que se esgota em si mesma, conhecimento esse que pode ser transmitido para a sociedade. Essa concepção de universidade vem sendo confrontada com outra, que procura submeter o conhecimento a uma lógica econômica (NEWMAN, 1891; JASPERS,1961; HABERMAS; BLAZEK, 1987; BALL, 2012, 2015; COLLINI, 2012, 2018).

Desde meados da década de 1960, iniciou-se uma tradição de pensamento na sociologia, que destacou o caráter estratégico do conhecimento nos desenvolvimentos econômico e tecnológico das sociedades. Naquele momento, surgiram também os trabalhos de Daniel Bell e Alain Touraine, que ressaltaram a centralidade do conhecimento como fonte de inovação na vida social e criaram o conceito de sociedade pós-industrial. Para isso, consideraram as novas estruturas sociais, que marcaram as modernas sociedades industriais, que passaram por uma série de transformações sociais a partir das últimas décadas do século XX. A despeito de diferenças teóricas entre eles, suas análises indicavam que, na sociedade pós-industrial, ocorreu a transformação de uma economia até então estruturada na produção de bens para outra na qual o setor de serviços adquiriu uma predominância quantitativa e social em relação aos setores econômicos primário e secundário. Nesse novo contexto, os trabalhadores não manuais constituíam a maior parte da força de trabalho, muito dos quais possuíam formação educacional de nível superior que os diferenciava dos trabalhadores manuais da sociedade industrial. Na perspectiva deles, a antiga classe operária encontrava-se em declínio quantitativo em função do avanço de uma economia de serviços que empregava trabalhadores com qualificação escolar. Para Bell e Touraine, surgiram novas modalidades de conflitos e formas insólitas de orientações socioculturais proporcionadas por uma sociedade que intensificou em larga escala padrões de consumo material e expandiu o Ensino Superior. Para ambos os autores, a universidade passou a ocupar uma posição institucional relevante, na medida em que as inovações econômica e social dependiam do 
conhecimento produzido em suas dependências, dando origem a um grupo social especializado na produção do saber, composto por cientistas e profissionais de nível superior. Embora os dois autores compartilhassem o ponto de vista da importância da produção de novos conhecimentos, impulsionada pela atividade de pesquisa no processo produtivo, possuíam visões distintas quanto aos desdobramentos da sociedade pósindustrial. A análise de Bell tinha como horizonte de análise a possibilidade de um grau razoável de integração social e institucional e um arrefecimento de disputas ideológicas. Por outro lado, Touraine, impactado pelos movimentos de maio de 1968, vislumbrava novas modalidades de conflitos, como a oposição entre intelectuais, que defendiam uma universidade fundada em valores humanistas, e profissionais, esses mais afinados com uma visão tecnocrática da educação,-conectada prioritariamente com o desenvolvimento econômico (BELL, 1960, 1973, 1978; TOURAINE, 1968, 1969, 1989)

A centralidade do conhecimento nas sociedades contemporâneas e a sua relação com o processo de produtividade econômica passou a ser ressaltada pela produção do discurso da knowledge society, ou seja, "sociedade do conhecimento", formulado por uma série de autores cujas análises possuem forte teor normativo. Nessa direção, Peter Drucker - então professor de administração da Universidade de Harvard e consultor de várias das maiores corporações dos Estados Unidos e do mundo, geralmente descrito como um dos fundadores da gestão empresarial moderna, com trabalhos traduzidos em escala mundial - ocupou posição importante na constituição e na divulgação da noção de knowledge society. (FAGERBERG et al., 2012; STRECKEISEN, 2009). Na visão de Peter Drucker, as mudanças da "sociedade pós-industrial" sinalizaram a emergência de uma "nova economia", na qual o conhecimento tornar-se-ia um fator estratégico de produção (DRUCKER, 1969, 1993). Para ele, a empresa industrial surgiu como instituição central da sociedade - na qual o administrador profissional, formado nas universidades, desenvolvia estilos inovadores na organização do esforço humano - e como modelo de organização de trabalho, que poderia ser aplicado em outras entidades, como governos, hospitais, universidades etc. Na sociedade pós-industrial, ainda segundo Drucker, os sistemas escolares e, destacadamente, a universidade assumiam papel crucial no processo de formação de profissionais qualificados em campos especializados e na dinâmica de inovação econômica e tecnológica. A concepção de knowledge society formulada por Drucker antecipou a proposta de introdução de mecanismos de gestão utilizados no mundo empresarial na administração das universidades, com vistas à obtenção de eficiência nos resultados de seus produtos. Isso viria a ganhar corpo, posteriormente, com o surgimento da noção de NPM, que passou a ter ampla divulgação mundial a partir dos anos 1990.

Os trabalhos desenvolvidos por Nico Stehr e Robin Mansell desempenharam também um papel importante na disseminação da noção de knowledge society. Enquanto Mansell focou sua atenção no desenvolvimento de novas tecnologias de comunicações eletrônicas, que possibilitaram a integração de processos econômicos e sociais em escala mundial, dando origem, segundo sua visão, a uma "sociedade da informação", Stehr visava fundamentar teoricamente a emergência da knowledge society, uma vez que, para ele, seu advento impactou as relações sociais, culturais e econômicas das sociedades contemporâneas (MANSELL, 1998; STEHR, 1988). Em seus trabalhos, Nico Stehr retomou argumentos elaborados por Daniel Bell, Peter Drucker, entre outros, e reforçou a perspectiva analítica que relaciona o papel do conhecimento no processo de incremento de produtividade econômica. Para ele, o surgimento histórico das sociedades do conhecimento não ocorreu de forma repentina, mas foi o resultado de um processo gradual, durante o qual determinadas características definidoras da sociedade industrial mudaram de tal forma que emergiu uma nova realidade.

O advento da sociedade do conhecimento sinalizou, em primeiro lugar, uma transformação radical na estrutura da economia. Na sociedade industrial, os processos produtivos eram governados por uma série de fatores que, segundo ele, estavam em declínio social, como oferta e demanda de produtos primários ou matérias-primas, importância do setor manufatureiro, que processa produtos primários, utilização 
intensiva do trabalho manual etc. Em sua visão, a sociedade moderna foi até recentemente concebida, principalmente, em termos de propriedade e trabalho e, com base nesses atributos, indivíduos e grupos foram constrangidos a definir sua participação na sociedade. Embora essas características não tenham desaparecido, foi acrescentado um novo princípio na estrutura social: o conhecimento científico, que, até certo ponto, desafia a propriedade e o trabalho como mecanismos constitutivos da sociedade. Nesse contexto, em função de seus fundamentos teóricos e empíricos e das possibilidades de aplicações práticas dos resultados de suas investigações, o conhecimento científico tornou-sefonte de valor agregado, adquiriu proeminência diante de outras formas de conhecimento e penetrou na maioria das esferas institucionais das sociedades contemporâneas. O conhecimento científico e seus desbobramentos tecnológicos tornaram-se importantes para a ação social e econômica, porque incrementam e aumentam a habilidade de how to do it, que constitui fator crucial no processo de produtividade econômica. Na sociedade do conhecimento, a maior parte da riqueza de uma empresa e/ou de um empreendimento está associada à sua capacidade de incorporar criatividade e informações em suas atividades. A noção de sociedade do conhecimento passou a ser divulgada mundialmente pelos trabalhos realizados por Unesco, OCDE e Banco Mundial e tem sido absorvida por uma pluralidade de atores, como pesquisadores, administradores de universidades, policy makers e outros, de forma, diga-se de passagem, acrítica, como se essa noção fosse um evento natural da vida social e desfrutasse de aceitação consensual nas ciências sociais. A incorporação dessa noção no léxico do Ensino Superior contemporâneo, revestida de uma aparente neutralidade conceitual, contribui para a conversão de uma visão parcial e particular sobre as universidades como expressão de um conhecimento legítimo a ser divulgado em escala global (UNESCO, 2005; WORLD BANK, 2002; OCDE, 1996).

A noção de sociedade do conhecimento caminhou pari passu com uma mudança do papel do Estado diante do Ensino Superior e, também, com o surgimento de um novo discurso a respeito do propósito da universidade e da forma de estruturar suas atividades. No contexto do Estado de Bem-Estar Social, a administração pública procurou oferecer serviços gratuitos aos cidadãos em educação, saúde e segurança. Com o avanço de políticas neoliberais, a partir de meados dos anos 1980, ocorreu uma mudança de rota, na qual o Estado privatizou uma série de serviços públicos e transformou seus cidadãos em clientes dos órgãos públicos privatizados. O papel e a posição das instituições de Ensino Superior e das universidades passaram a ser considerados um locus estratégico no processo de novos conhecimentos e de inovações tecnológicas na acirrada competitividade impulsionado pelo processo de globalização. Por volta de 1990, a noção de NPM surgiu no vocabulário da adminstração pública, sinalizando que a eficiência e a qualidade dos serviços públicos poderiam ser impulsionadas pela introdução de modos do setor privado. Nessa modalidade de organização do trabalho, privilegiam-se monitoramento de medição de desempenho dos agentes, introdução de sistemas de auditoria, concentração nos objetivos de eficiência, aumento na hierarquia no interior das instituições e centralização de decisões no topo da hierarquia das instituições (POLLITT; BOUCKAERT, 2004; HOOD et al., 2004). Num cenário de restrições orçamentárias vivenciadas por universidades em várias partes do mundo em função de retração de despesas públicas em áreas sociais, vêm sendo introduzidas reformas, visando aumentar a eficiência de seus procedimentos, a produtividade de seus produtos e a diversificação de fontes de financiamento de forma a diminur sua dependência de fundos públicos (COLLINI, 2018; SEEBER, 2015).

Sob inspiração do NPM, cria-se a expectativa de que as universidades estabeleçam, de forma clara, seus objetivos organizacionais, para poder operar como ator estratégico no contexto de competição acadêmica nos níveis local, nacional e global. Em termos de organização do trabalho, o NPM implica profundas transformações, uma vez que, ao longo da trajetória das universidades, as decisões sobre os rumos da instituição foram tomadas em seus corpos colegiados, sob os auspícios dos membros docentes que os integram, ao passo que, no novo cenário, vem ocorrendo uma centralização hierárquica nos processos 
decisórios, cada vez mais constituída por um corpo de profissionais especializados em gestão universitária. Nesse contexto, os acadêmicos estão submetidos de forma crescente à pressão de produtividade em termos de publicações de suas pesquisas em periódicos internacionais de prestígio em suas respectivas áreas, auferidas por agências nacionais de avalição. A partir do surgimento dos rankings globais, por volta de 2003, as universidades passaram a competir por prestígio acadêmico no plano internacional. Intensificou-se a pressão nos docentes para aumentar a visibilidade das instituições por meio de suas publicações.

O trabalho acadêmico, que, por um longo período, foi realizado de forma individual e sem grandes pressões externas, também vem passando por mudanças significativas nesse contexto, na medida em que é estimulado a ser desenvolvido de forma coletiva, muitas vezes pautado por imperativos de financiamentos obtidos por parcerias com empresas e/ou órgãos governamentais com duração limitada. Os docentes são estimulados a se tornarem empreendedores acadêmicos, pressionados a obter recursos externos para suas pesquisas e, de forma indireta, para as universidades. Nesse contexto, os trabalhos denominados triple helix, realizados por Loet Leydesdorff e Henry Etzkowitz, são sugestivos, no sentido de situar os docentes como um elo da corrente das relações entre governo, universidade e indústria na diversificação do financiamento e da inserção do Ensino Superior na dinâmica do processo econômico (ETZKOWITZ, 2008; ETZKOWITZ; LEYDESDORFF, 1998).

Em termos de financiamento também ocorrem mudanças importantes, uma vez que a alocação de recursos para as universidades é baseada de forma crescente em indicadores de resultados, como número de estudantes titulados e número e impacto de publicações de pesquisa. Além disso, as universidades são levadas a diversificar suas fontes de financiamento por meio de cobrança de anuidades de alunos e parcerias com setores empresariais e/ou governamentais. Por outro lado, a formação acadêmica orienta-se para dotar os estudantes de habilidades profissionais voltadas a atender demandas do campo acadêmico e à sua empregabilidade. As transformações do Ensino Superior, impulsionadas pela knowledge economy e pelo NPM, tendem a incentivar uma cultura de empreendedorismo tanto nos docentes quanto nos estudantes, por meio do estímulo a uma série de condutas a ser praticadas no interior das universidades e além de seus muros, como comportamentos de ousadia e vigor na condução dos seus projetos individuais. O self-empreendedor deve procurar governar a si próprio e seus interesses acadêmicos e profissionais de forma calculada, como condição necessária para se movimentar numa sociedade neoliberal, na qual os indivíduos em situação de desamparo social devem lutar pela sua própria realização pessoal (ROSE, 1998).

A introdução de procedimentos do meio empresarial na universidade tem afetado a subjetividade dos docentes e dos estudantes. Eles são impulsionados a interiorizar o culto à velocidade, na medida em que são cada vez mais pressionados a usar de modo racional seu tempo tanto de trabalho quanto livre para absorver informações, acumular publicações, envolver-se em trabalhos de comitês acadêmicos, obter subsídios para seus projetos, participar de seminários e se tornar visível em sua área. O uso intensivo e racional do tempo tornou-se condição importante na universidade.-Docentes e estudantes estão em processo de competição manifesta ou latente com seus pares, ao mesmo tempo que as universidades que os abrigam concorrem com outras instituições, no plano local, no nacional e/ou no global. Ao mesmo tempo, estudantes e docentes são pressionados a interiorizar o culto à eficiência, que representa valor crucial no mundo dos negócios e cuja importância aumentou visivelmente sob a globalização econômica, exaltando a aptidão de responder de forma competente aos problemas apresentados nos campos profissionais como uma finalidade em si mesma. ${ }^{8}$ 


\section{Considerações Finais}

Durante longo período, o Ensino Superior e as universidades foram considerados importantes instituições nacionais, em função da formação da cultura e da identidade próprias, bem como devido ao encargo que assumiram de contribuir para o desenvolvimento econômico e de quadros profissionais para diferentes atividades sociais dos seus países. Essa imersão histórica do Ensino Superior na vida de suas respectivas sociedades nacionais de certa forma dificultou uma percepção analítica do impacto do processo de globalização - que se tornou socialmente visível a partir do final dos anos 1980 - na sua dinâmica. O Ensino Superior continuou a ser analisado levando-se em consideração apenas os contornos de suas sociedades nacionais.

Este artigo destacou que, no contexto da globalização - compreendido conceitualmente como um processo multidimensional, não linear, que pode assumir diferentes configurações no interior das sociedades -, os fenômenos econômicos, políticos, culturais e acadêmicos tendem a alongar-se além das fronteiras nacionais, de tal forma que o Ensino Superior encontra-se também abarcado pelo turbilhão de macrotransformações ocorrendo nas sociedades contemporâneas. Nessa direção, salientou-se que uma das mudanças significativas no Ensino Superior foi a constituição de um novo espaço de sua atuação, ou seja, a emergência de um espaço transnacional de Ensino Superior, que abarca, de forma simultânea, os níveis local, nacional e global superior dessa modalidade de ensino. Isso implica uma conexão entre a existência de milhares de instituições espalhadas pelo mundo com as políticas educacionais de seus respectivos países, que mantêm relações de reciprocidade com o espaço global, onde operam organismos multilaterais, empresas transnacionais de serviços educacionais, deslocamento de universidades estrangeiras em direção aos cinco continentes, formação de consócios de universidades provenientes de vários países etc.

Esse novo espaço transnacional do Ensino Superior tem sido impactado por fenômenos constitutivos da globalização, com o desenvolvimento de novas tecnologias de comunicações, implicando mudanças nas dimensões tanto temporais quanto espaciais, eliminando barreiras e propiciando a intensificação de intercâmbio de ideias e conhecimentos A mobilidade acadêmica de docentes tornou-se mais frequente por meio do aumento de conferências internacionais e do estabelecimento de networks de pesquisadores, em diferentes países, que trabalham em uma mesma temática, dando origem a publicações conjuntas.

$\mathrm{O}$ artigo salientou que esse novo espaço transnacional do Ensino Superior tem sido marcado por um processo de competitividade interna nas instituições, entre elas e entre os países; pelo empenho na obtenção de recursos financeiros adicionais, incluindo a atração de estudantes estrangeiros; pela busca por prestígio acadêmico pautada pelos rankings nacionais e globais; e pela persistente persecução de visibilidade e reconhecimento acadêmicos por parte dos docentes e dos estudantes.

O processo de globalização impulsionou o Ensino Superior e as universidades a se engajarem numa lógica de comportamento de mercado, num movimento no qual as fronteiras institucionais entre Estado, mercado e sociedade civil se tornam cada vez mais porosas. Na medida em que o Estado, na esteira de políticas neoliberais, passou a diminuir o financiamento público para as universidades sob sua responsabilidade, elas têm sido pressionadas a manter parcerias de projetos com empresas nacionais e/ou com corporações internacionais, com órgãos do Estado e com entidades da sociedade civil, com vistas a comercializar seus produtos, bem como estender suas ações além de seus territórios em busca de recursos. Nessa direção, as universidades têm se tornado um dos locais centrais que nutrem a dinâmica do processo de globalização, na medida em que aglutinam fluxos de informações, ideias e pessoas, possibilitando a constituição de redes entre indivíduos e instituições de diferentes partes do mundo. As universidades tornaram-se um centro vital de ensino e pesquisa, produção de novas tecnologias para uma economia que é pela aceleração de inovações produtivas. 
Não se pode desconsiderar que algumas dessas universidades - as denominadas word class universities, que ocupam as posições de destaque nos rankings globais - funcionam como celeiros da produção de elites acadêmicas e profissionais habilitadas a atuar em instituições de alcance global. Nesse processo, as instituições nacionais de Ensino Superior, impactadas pelas forças econômicas e culturais do processo de globalização, são confrontadas com processos de isomorfismo acadêmico; ou seja, são pressionadas a adotar procedimentos praticados pelas instituições que ocupam posições de poder no espaço transnacional do Ensino Superior. Isso quer dizer que as instituições mais bem-posicionadas nos rankings globais exercem um efeitodemonstração para as universidades numa escala mundial. O artigo destacou que a introdução do NPM adotado por essas instituições tem reverberado na cultura acadêmica das universidades no sentido de maior eficiência como um fim em si mesmo, pressionando docentes e estudantes a aumentarem seus padrões de produtividade e utilizarem de forma mais racional o tempo dedicado aos afazeres acadêmicos.

O legado da concepção de universidade, inaugurada por Humboldt, permite repensar criticamente processos e orientações de ideias que vêm pautando a reconfiguração do Ensino Superior contemporâneo, na medida em que salienta que a identidade institucional assenta-se na produção e na transmissão do conhecimento, cujo valor não deve ser medido a partir de critérios de utilidade, mas avaliado pelas suas qualidade e relevância acadêmica. Não obstante, a dimensão profícua desse modelo necessita também ser revista criticamente, pois sua gênese coincidiu com a existência de uma universidade destinada, basicamente, a um pequeno círculo da elite econômica e/ou cultural. Não procede, nos dias atuais, conceber as universidades como instituições isoladas de questões econômicas, políticas e culturais relevantes das sociedades nacionais e do mundo contemporâneo. A revisão dessa concepção pode propiciar percursos alternativos possíveis, com vistas a estabelecer um delicado e complexo equilíbrio entre a preservação da autonomia institucional das universidades diante das múltiplas demandas econômicas e políticas com as quais elas são confrontadas em várias partes do mundo.

Apesar de pressionadas a responder de forma utilitária às demandas do campo econômico, é preciso assinalar que, em função do incremento de fluxos de conhecimentos, as universidades comportam a possibilidade da produção de um conhecimento crítico com relação à própria dinâmica da globalização. Ao lado de sua interação com o processo produtivo, as universidades têm fornecido uma contribuição cultural e cognitiva, que constitui a base para a formação de vários movimentos sociais nos níveis local, nacional e global, que lutam contra as desigualdades econômicas, sociais, culturais e educacionais do mundo contemporâneo.

\section{Notas}

1. A propósito da incorporação da temática da globalização na sociologia, consultar Dufoix (2018). Quanto aos trabalhos posteriores sobre a temática da globalização, ver Martell (2007).

2. Para uma avaliação crítica dos conceitos de knowlwdge Society e new public management, ver Amaral (2018) e Peters e Olssen (2015).

3. O presente artigo incorpora a perspectiva de uma sociologia reflexiva proposta por Pierre Bourdieu como condição para a realização de um trabalho científico. Ver, a esse propósito, Bourdieu $(2001,2015)$ e Bourdieu e Wacquant (1992).

4. Uma avaliação crítica do nacionalismo metodológico pode ser encontrada em Delanty (2009), Chernilo (2011) e Dale e Robertson (2009). 
5. Com relação às relações reciprocas entre os níveis local, nacional e global, ver Marginson (2011).

6. A propósito de princípios que pautaram a Universidade de Berlim, criada em 1810, ver os trabalhos de Collini (2018), Delanty (2002) e Ringer (1969).

7. Parte expressiva da bibliografia sobre os rankings globais oscila entre uma perspectiva analítica e uma postura valorativa. Ver, a respeito dessa postura, os trabalhos de Ellen Hazelkorn $(2011,2014)$.

8. Com relação ao processo de aceleração social provocado pela dinâmica da globalização e seus efeitos em diferentes esferas sociais, ver os trabalhos de Wajcman (2015), Rosa (2013), Tomlinson (2007).

\section{Referências}

AMARAL, A. Universities and the knowledge society revisited. In: BARNETT, R.; PETERS, M. A. (orgs.). The idea of university: contemporary perspectives. Oxford: Peter Lang, 2018.

BALL, S. Global Education Inc: new policy networks and the neoliberal imaginary. London: Routledge, 2012. BALL, S. Living the neo-liberal university. European Journal of Education, Abingdon, v. 50, n. 3, p. 258261, 2015. https://doi.org/10.1111/ejed.12132

BECK. U. The cosmopolitan vision. Cambridge: Polity Press, 2006.

BECK. U. The metamorphosis of the world. Cambridge: Polity Press, 2016.

BELL, D. The end of ideology. New York. Free Press, 1960.

BELL, D. The coming of post-industrial society: a venture in social forecasting. New York: Basic Books, 1973. BELL, D. The cultural contradictions of capitalism. New York: Basic Books, 1978.

BJARNASON, S. Borderless Higher Education. In: KING, R. G. (org.). The university in the global age. London: Palgrave, 2004.

BOURDIEU, P. Science de la science et réflexivité. Paris : Raisons D’agir, 2001.

BOURDIEU, P. Sociologie générale. Cours au Collège de France 1981-1983. Paris : Raisons D’agir, 2015. v. I. BOURDIEU, P. ; WACQUANT, L. Réponses : pour une anthropologie réflexive. Paris : Seuil, 1992.

CHARLES, C. ; VERGER, J. Histoire des universités (XIIe-XXIe siècle). Paris. Presses Universitaires France, 2012.

CHERNILO, D. The critique of methodological nationalism: theory and history. Thesis Eleven, Clayton, v. 106, n. 1, p. 98-117, 2011. https://doi.org/10.1177/0725513611415789

CHERNILO, D. Debating humanity: towards a philosophical sociology. Cambridge: Cambridge University Press, 2018.

COLLINI., S. What are universities for? London: Penguin Books, 2012.

COLLINI., S. Speaking of university. London: Verso, 2018. 
CUNNINGHAM et al. The business of borderless education. Canberra: Department of Employment, Education, Training and Youth Affairs, 2000.

DALE, R.; ROBERTSON. S. Beyond methodological "isms" in comparative education in an era of globalization. In: COWEN, R.; KAZAMIAS, A. M. (orgs). International handbook of comparative education. Dordrecht: Springer, 2009.

DELANTY, G. The university in the knowledge society. London: Open University Press, 2002.

DELANTY, G. The cosmopolitan imagination: the renewal of critical theory. Cambridge: Cambridge University Press, 2009.

DRUCKER, P. F. The age of discontinuity: guidelines to our changing society. New York: ButterworthHeinemann, 1969.

DRUCKER, P. F. Post-capitalist society. New York: Harper Business, 1993.

DUFOIX, S. Premiers éléments pour une sociologie historique des theories de la globalisation. In : CAILLE, A.; VANDENBERGHE, F. (orgs.). Des sciences sociales á la science sociale : fondements anti-utilitaristes. Lormont : Éditions le Bord de l'Eau, 2018.

ELLIOT, A. Reinvention. New York: Routledge, 2013.

ETZKOWITZ, H. The triple helix: university-industry-government innovation in action. London: Routledge, 2008.

ETZKOWITZ, H.; LEYDESDORFF. L. The triple helix as a model for innovation studies. Science Public Policy, Washington, v. 25, n. 3, p. 195-203, jun. 2004. https://doi.org/10.1093/spp/25.3.195

FAGERBERG. L. Exploring the emerging knowledge base of 'the knowledge society'. Research Policy, Amsterdam, v. 41, n. 2, p 1121-1131, 2012. https://doi.org/10.1016/j.respol.2012.03.007

GARRETT, R. International branch campuses: success factors. The observatory on borderless higher education. Albany: The State University of New York at Albany, 2017.

HABERMAS, J.; BLAZEK, J. The idea of the university: learning process. New German Critique, n. 41, p. 3-22, 1987. (Special Issue: The Critique of the Enlightenment). https://doi.org/10.2307/488273

HAZELKORN, E. Rankings and the reshaping of higher education. London: Palgrave, 2011.

HAZELKORN, E. Reflections on a decade of global rankings: what we've learned and outstanding issues. European Journal of Education, Abingdon, v. 49, n. 1, p. 12-28, Nov. 2014.

HOOD, C. et al. (orgs). Controlling modern government. London: Edward Elgar, 2004.

IIE CENTER FOR ACADEMIC MOBILITY. A world on the move: trends in global student mobility. New York: IIE, 2018. v. 2.

JASPERS, K. The idea of a university. London: Peter Owen, 1961.

KENNEDY, M. Globalizing knowledge: intellectuals, universities and public transformation. Stanford: Stanford University Press, 2015. 
KING, R. (org.). The university in the global age. London: Palgrave, 2004.

KNIGHT, J. GATS, trade and higher education. London: The Observatory of Borderless Higher Education, 2003.

KNIGHT, J. Higher education in turmoil: the changing world of internationalization. Rotterdam: Sense Publishers, 2008.

KOSMUTZKY, A.; PUTTY, R. Transcending borders and traversing boundaries: a systematic review of the literature on transnational offshore cross-border and borderless higher education. Journal of Studies in International Education, Thousand Oaks, v. 20,n.91, p. 8-33, 2016.https://doi.org/10.1177/1028315315604719 LEMERT, C. Globalization. An introduction to the end of the known world. London: Paradigm Publishers, 2015.

LUKE, A. Generalizing across borders: policy and the limits of educational science. Educational Researcher, Washington, v. 40, p. 367-377, Dec. 2011. https://doi.org/10.3102/0013189X11424314

MANSELL, R. Knowledge societies: information, technology for sustainable development. Oxford: Oxford University Press, 1998.

MARGINSON, S. Imagining the global. In: MARGINSON, S.; NAIDOO, R.; KING, R. (orgs.). Handbook on globalization and higher education. Massachusetts: Edward Elgar Publishing, 2011.

MARGINSON, S. University rankings and social science. European Journal of Education, Abingdon, v. 49, n. 1, p. 45-59, 2014. https://doi.org/10.1111/ejed.12061

MARTELL, L. The third wave in globalization theory. International Studies Review, Maiden, v. 9, n. 2, p. 173-196, 2007. https://doi.org/10.1111/j.1468-2486.2007.00670.x

NEWMAN, J. H. The idea of a university. London: Longmans, 1891.

OCDE [ORGANISATION DE COOPERATION ET DE DEVELOPPEMENT ÉCONOMIQUES]. The knowledge-based society. Paris: OCDE, 1996.

PALFREYMAN, D.; TAPPER, T. Structuring mass higher education: the role of elite institutions. London: Routledge, 2009.

PETERS, M.; OLSSEN, M. Neoliberalism, higher education and the knowledge economy: from the free market to knowledge capitalism. Journal of Education Policy, London, v. 20, n. 3, 2015. https://doi. org/10.1080/02680930500108718

POLLITT, C.; BOUCKAERT, G. Public management reform. Oxford: Oxford University Press, 2004.

RAUHVARGERS, A. Global university rankings and their impact. Brussels: European University Association, 2013.

RINGER, F. The decline of the German Mandarins: the German academic community, 1890-1933. Cambridge: Harvard University Press, 1969.

ROSA, H. Social acceleration. New York: Columbia University Press, 2013. 
ROSE, N. Inventing ourselves: psychology, power and personhood. Cambridge: Cambridge University Press, 1998.

SASSEN, S. A sociology of globalization. New York: W. W. Norton \& Company, 2007.

SASSEN, S. Expulsions: brutality and complexity in the global economy. Cambridge: Harvard University Press, 2014.

SAUDER, M.; ESPELAND, W.N. The discipline of rankings: tight coupling and organizational change. American Sociological Review, Philadelphia, v.74, n. 1, p.63-82, Feb. 2009. https://doi.org/10.1177/000312240907400104

SHAHJAHAN, R. A. The roles of international organizations in globalizing higher education policy. In: SMART, J.; PAULSEN, M. (orgs.). Higher education: handbook of theory and research. London: Springer, 2012. p. 369-407.

STEHR, N. Knowledge societies. London: Sage, 1988.

STRECKEISEN, P. Knowledge society - contemporary capitalism's fanciest dress. Analysis and Kritik, Wiesbaden, v. 31, n. 1, p. 181-197, 2009. https://doi.org/10.1515/auk-2009-0112

TOMLINSON, J. The culture of speed: the coming of immediacy. London : Sage Publications, 2007.

TOURAINE, A. Le mouvement de mai 1968 ou le communisme utopique. Paris : Seuil, 1968.

TOURAINE, A. La société post-industrielle. Paris : Denoël, 1969.

TOURAINE, A. Mouvements sociaux d'aujourd'hui : acteurs et analystes. Paris : Éditions de l'atelier, 1989.

TURNER, B. S.; ELLIOT. A. A. On society. Cambridge: Polity Press, 2012.

TURNER, B. S.; KHONDKER, H. Globalization: East and West. London: Sage, 2010.

UNESCO [ORGANIZAÇÃO DAS NAÇÕES UNIDAS PARA EDUCAÇÃO, CIÊNCIA E CULTURA]. Origin. Toward knowledge societies. Paris: Unesco, 2005.

WAJCMAN, J. Pressed for time. The life of digital capitalism. Chicago: The University of Chicago Press, 2015. WILDAVSKY, B. The great brain race: how global universities are reshaping the world. New Jersey: Princeton University Press, 2010.

WORLD BANK. Knowledge for development, constructing knowledge societies: new challenges for tertiary education. Washington: World Bank, 2002.

WEBER, M. Methodology of social sciences, Illinois: The Free Press of Glencoe, 1949.

\section{Sobre o Autor}

Carlos Benedito Martins é doutor em Sociologia pela Universidade de Paris V (René Descartes) (1986). Realizou Pós-doutorado em Sociologia na Universidade de Columbia (2006) e na Universidade de Oxford (2012). Foi Visiting Scholar na Universidade de Columbia (janeiro/março de 2008 e fevereiro/março de 2010), no Instituto de Ciências Sociais da Universidade de Lisboa (janeiro/fevereiro de 2009, novembro 
de 2010 e setembro de 2012), na Universidade Livre de Berlim (janeiro/fevereiro de 2014), na Universidade de Hong Kong (fevereiro/março de 2016) e na Universidade Nacional de Singapura (fevereiro de 2017), além de, diversas vezes, na École des Hautes Etudes en Sciences Sociales (último período em abril/junho de 2018). Foi Presidente da Sociedade Brasileira de Sociologia (2015-2017, reeleito para o período 2017-2019). Recebeu o Prêmio ANPOCS de Excelência Acadêmica Antônio Flávio Pierucci em Sociologia (2020). Áreas de atuação: Teoria Social; Sociologia do Ensino Superior; e Sociologia dos Intelectuais.

Recebido: 28 jul. 2020

Aceito: 17 nov. 2020 